\title{
Confusion and Making Sense of Menstruation: A Micro-level Study of Village Khagawal, Chandauli District, Uttar Pradesh
}

Sumedha ${ }^{* *}$ and Suman Singh ${ }^{*}$

\section{Abstract}

Menstruation is a natural process which has significant and irrevocable changes on a woman's life. Navigating the entire process is no small feat, and the added confusion in the age of information overload often complicates the situation rather than simplifying it. In India, discourses surrounding menstruation are still restricted to sanitary napkins while overlooking menstrual disorders, understanding and examining the agencies responsible for it. Many a time, ancient pearls of wisdom are being dismissed as taboos without apprehending its deeper sciences which helped women in traversing the entire process since time immemorial. This research is an attempt to view menstruation holistically by giving importance to a woman's personal experiences and to find out how menstruation is integrated into the local culture. To accomplish the research, we conducted a questionnaire survey amongst 40 females aged 13-49 years and three focus group discussions to explore the coping mechanisms, the grass-root problems the rural girls and women face during menstruation in village Khagawal located in Chandauli district of Uttar Pradesh. The findings revealed that rudimentary information concerning menstruation was present amongst the respondents - the respondents are aware of the traditional knowledge and ways but completely ignorant regarding the scientific roots of the practices. Some facets of hygiene need to be addressed.

Keywords: Menstruation; Menstrual Disorders; Questionnaire Survey; Focus Groups; India

\footnotetext{
${ }^{\dagger}$ Research Scholar (UGC-JRF), Department of Geography, Institute of Science, Banaras Hindu University, India

${ }^{*}$ Corresponding Author, Email: sumedhachaturvedi1993@gmail.com

${ }^{¥}$ Associate Professor, Department of Geography, Institute of Science, Banaras Hindu University, India, Email: sumansingh.bhu@gmail.com

(C)2019 Sumedha \& Singh. This is an Open Access article distributed under the terms of the Creative Commons Attribution License (http://creativecommons.org/licenses/by/2.0), which permits unrestricted use, distribution, and reproduction in any medium, provided the original work is properly cited.
} 


\section{Introduction}

Unlike the widely debated discourse on violence against Indian and South Asian women such as sexual harassment in public spaces (Bhattacharyya, 2009; 2013a,b; 2015; 2016; 2018); rape (Bhattacharyya, 2015; 2016; Singh, 2018); domestic violence (Bhattacharyya, 2015; Bhattacharyya et al., 2018; Das et al. 2015; 2016; 2019; Rao, 1998;Vauquline, 2015 ); dowry (Bloch and Rao, 2002; Rao, 1993; Srinivasan, 2005); female foeticide (Bhattacharyya, 2014a; Varma, 2013; Vishwanath, 1996), menstruation is still considered a taboo topic. Historically in India, menstruation is discussed in religious and philosophical works such as Yajurveda Tattiriya Samhita (2.5.1) and Shatpatha Brahman as well as in law books like Dharmsutras of Baudhayana (2.2.4.4) and Vashishtha (5.5) (Sridhar, 2019). It has been discussed in depth in Ayurvedic texts by Sushruta (Bhishagratna, as cited in Sridhar, 2019) and Charaka (Loon, as cited in Sridhar, 2019) in their Samhitas and treated it as a physiological process. However, in the recent times, there has been emerging discussions on menstruation (Dambhare, Wagh \& Dudhe, 2012; Garg, Sharma \& Sahay, 2001; Joseph, 2014; 2016; 2017; Kansal, Singh \& Kumar, 2016; Pugalenthi, Senthil, Jayakumar \& Pandiammal, 2013; Raina \& Balodi, 2014; Shah et al., 2013; Sridhar, 2019 Thakre, Thakre, Ughade, Thakre, 2012; Yasmin, Manna, Malik, Ahmed \& Paria, 2013). Further mainstreaming of the discourse occurred through Padma Shri awardee Arunachalam Muruganantham, the social entrepreneur from Coimbatore, Tamil Nadu, who has developed low-cost sanitary napkins as compared to commercial sanitary napkins. He gained widespread appreciation (Coast, Strong \& Lattof, 2019) and international fame for his efforts which made him a household name. His life has been captured in 2018, motion picture, 'Padman', directed by R. Balki, and acted by Akshay Kumar, Sonam Kapoor and Radhika Apte. This picture is an excellent demonstration of how the villagers, whose social and cultural training are embedded in tacit taboo about menstruation (Koner, 2018) treated the pad man where he received vehement unacceptability from his society. Evidently, the cost of these napkins are almost one-third of the cost of commercial napkins. Padman's low-cost, mini machines have already been installed in 23 states, and he aims to expand his service to 106 nations; however, these are still at an embryonic state. The passion for innovating such low-cost sanitary napkins emerged with the aim of building awareness about maintaining hygienic menstruation practices by all women who fail to afford high-cost commercial napkins. However, more rigorous research is required to examine the extent of the quality of Padman's low-cost napkins.

Another similar 2018 documentary short film entitled Period. End of Sentence directed by Rayka Zehtabchi won the Academy Award for Best Documentary (Short Subject) in 2018. This short film gained inspiration from Arunachalam Muruganantham, which showcases the silent sexual revolution by building and selling lowcost, affordable and most importantly, ecofriendly biodegradable sanitary pads amongst women.

Notwithstanding, in the post-economic reforms of the 1990s, there is increased attention on women's empowerment through education and employment (Bhattacharyya, 2009; 2013a; Dyson, 2019). However, in commercial advertisements for feminine hygiene products, menstruation is depicted as lugubrious portraying a subdued female body that hinders their mobilities during their days of menstruation and in social discussions, menstruation continues to be pictured as oppressive to females. Widespread discussion on menstruation is undoubtedly welcome. Nevertheless, most of the emergent discourses on menstruation in India, are still lopsided as they favour, profoundly, some aspects such as marketing of feminine hygiene products without keeping account of its quality and nonbiodegradability and ignore others like proper quality checks of low-cost sanitary napkins, indepth understanding of Menstrual-related Symptoms (MRSs) and its impact which 
according to Schoep et al. (2019) need to be examined as few studies have been conducted to study absenteeism and presenteeism due to MRSs among the female population, thereby neglecting the subjective and lived experiences of women often discrediting their knowledge.

Menstruation is a natural process that women undergo for a significant period of their lives. Emphasising the importance which it holds, Sridhar (2019) states that menstruation due to its relation with fertility and motherhood has an intricate association with womanhood indicating that as individuals there are specific differences between men and women on many levels. Sridhar (2019) has further discussed the critical role which menstruation plays in shaping the perception regarding a woman by various cultures and societies in addition to the relationship between man and woman, including the role women have in societies.

In this context, Kansal et al., (2016) mention that the lives of adolescent girls change with the onset of menstruation or menarche, which is a part of the maturation process, bringing a host of physical, psychological and physiological changes, which is often, "culturally defined as the indicator of girl's maturity and readiness for marriage and sexual activity" (Kansal et al., 2016, p. 39). Undoubtedly, menarche holds much importance in a woman's life. It moulds a woman's behaviour - attitude and perception regarding menstruation as a cyclical process. Society plays a vital role in shaping such attitudes - the way societies perceive menstruation, set the course for a woman's response to it. Beliefs and values dictated by customs, rituals, and traditions are essential components of attitudes (Bhattacharyya, 2009; Bhattacharyya and Singh, 2018; Eagly \& Chaiken, as cited in Hoerster, Chrisler \& Rose, 2008). Expectations about bodily functions shape the attributions people make about the causes and meanings of physical and emotional experiences (Koeske \& Koeske, as cited in Hoerster et al., 2008). In this research, we probe about making sense of menstruation as a bodily function, its management by rural women dwelling in a village in eastern Uttar Pradesh and examining different methods through which they cope with various MRSs and menstrual disorders.

Many contemporary studies and discussions on menstruation are centred on biology. Conventional knowledge, cultural practices and lived experiences along with spiritual aspects are bracketed with taboos and superstition. The key problem centres around the fact that the issue has recently been observed solely from a biological lens without acknowledging other aspects of the process like subjective experiences, cultural knowledge and spirituality, which are rather reduced to taboos and superstitions (Marglin, 1994; Joseph 2014, 2016; Sridhar, 2019). "It is easy in today's world to forget that our menstrual cycle is all about reproduction" (Madsen, 2011, para 3). Marglin (1994) has remarked that menstruation is not only related to reproduction but mainly with generation and regeneration, further commenting that scientific knowledge has deeply influenced the way in which menstruation is experienced, expressed and understood. Madsen (2011) points to the importance of connection women must establish with their cycles and the need for an environment which focusses on rest during menstruation. The rest helps women in navigating their body and mind through the entire process; understanding their bodies by establishing deep connections with it, at the same time, expressing discontent at the present state of affair, which sends a message that all the above-mentioned particulars are not much necessary and therefore can be ignored. "But perhaps we should consider looking at how women who came before us treated themselves during their cycles for some helpful pointers" (Madsen, 2011, para 1).

Though a large number of studies on menstrual health and hygiene is taking place in developing countries like Kenya, Nepal, Nigeria, Bangladesh and India but these discourses are driven by the entities from developed nations (Joseph, 2016). As stated above, Indian scholars conducting research on menstruation have assessed the condition of menstrual hygiene in the country (Garg et al., 2001; Kansal et al., 2016; Pugalenthi 
et al., 2013; Raina et al., 2014; Shah et al., 2013, Yasmin et al., 2013). These studies have found that sanitary napkins are not as widely used as cloth in India and, therefore concluded that Indian women lag in Menstrual Hygiene Management (MHM). The scholars (Garg et al., 2001; Kansal et al., 2016; Raina et al., 2014; Shah et al., 2013) surveyed different parts of India and found old cotton clothes or certain special clothes to be more popular among women than sanitary napkins. Some of these studies considered the use of sanitary napkins as an indicator of better menstrual hygiene practices. These studies, however, did not collect data on the frequency of change of the absorbent and the habit of handwashing before and after the change of preferred absorbent. The point of concern is that studies do not clearly define what constitutes safe menstrual hygiene or discuss sustainable environmentally friendly disposal methods. Earlier, Hoerster et al., (2008) tried to examine the attitudes and experiences regarding menstruation by doing a comparative study between the USA and India. This study mentions that Chandra and Chaturvedi (1992) adapted the Brooks-Gunn and Ruble's (1980) (as cited in Hoerster et al., 2008) multidimensional Menstrual Attitude Questionnaire (MAQ) in their studies conducted in India. Comparisons by Chandra and Chaturvedi (1992) of Indian data to mean scores published by Brooks-Gunn and Ruble (1986) indicated that Indian women hold more firmly than American women on their view that menstruation is natural, and Indian women were more likely than American women to deny the effects of menstruation. However, the two groups did not respond to the same version of the questionnaire (as cited in Hoerster et al., 2008).

Against this backdrop, this micro-study is an endeavour to better understand the sense that menstruation as a natural body function makes, taking into consideration the conventional values and beliefs along with scientific knowledge. In so doing, it attempts to examine the ideas behind the conventional values and beliefs, relating to menstrual practices in Khagawal village of Chandauli District, Uttar Pradesh. The study was conducted to examine the knowledge of rural women and girls about menstruation and practices adopted by them. It is an attempt to understand the subjective experiences of females and whether and how traditional practices have changed with the passage of time.

The research begins with a brief description of the study area. This follows a discussion on methodology. In the final sections, we critically discuss the results of our research.

\section{Profile of the Study Area}

Khagawal is a village located in Chandauli district of Uttar Pradesh, which is geospatially found between 25.29N Latitude and 83.26E Longitude. Revenue jurisdiction of Khagawal vests in Sakaldiha Tehsil of Chandauli district. Sakaldiha is also its development block. Khagawal lacks proper and constant connectivity to the nearest urban area Chandauli. Its distance from the district headquarters Chandauli is nearly $4 \mathrm{~km}$, and $3 \mathrm{~km}$ from the Tehsil headquarter. The village is devoid of any medical facility as it has neither a Primary Health Centre (PHC) nor any Medical Practitioner. The female literacy in the village is $54.74 \%$ which is quite low and even lower than the district rural female literacy rate, which stands at $60.35 \%$ (Census of India, 2011). District Chandauli is known for paddy cultivation and rice production. This village is no different and has a totally agriculture-based economy. Some of the villagers are involved in service sector in the nearest district headquarter, Chandauli or the nearby district, Varanasi.

\section{Methodology}

The survey was carried out in February 2016. At first, a pilot survey was conducted to understand the ground realities and for planning the sample design. Primary data was collected accordingly. In total, 40 females (13-49 age group) were sampled. The purpose of the study and the nature of the information to be extracted were explained to the participants. The survey was conducted using interview schedules with a list of questions linked to socio-economic profile of the respondents, age at menarche, awareness about menstruation, source of information, practices, dietary habits, restrictions in daily 
routine. Questions related to respondents' own perceptions were also included. The questions were both open-ended and close-ended to elicit as much information as possible. The demographic profile of the village was retrieved through the Census of India, 2011. Three intense Focus Group Discussions (FGDs) were conducted to examine the personal experiences, stories and myths related to menarche and menstruation. The respondents along with few women from the older age group were selected for the same. They were informed regarding the nature of the study and were told not to disclose their names and information, which were of personal nature. Permission was taken from guardians of minor girls who were being interviewed. As women tend to maintain privacy on this issue, FGDs were conducted to know their opinion and attitude towards menstruation and to identify the problems prevalent among the girls and women of the village. The next section critically analyses the findings.

\section{Results and Discussion}

One of the first findings demonstrate that the majority of the respondents were attaining menarche in between 14 to 17 years with a mean age of 14 years, which is higher than the mean age as reported by Banerjee et al. (2007); Dambhare et al. (2012); Yasmin et al. (2013) and Kansal et al. (2016). The findings go on to reveal that $65 \%$ of the participants received knowledge about menses chiefly from their mothers; other sources were relatives $(25 \%)$ and friends $(10 \%)$. This finding is different from the observations made by Kansal et al. (2016) where 55\% respondents were receiving knowledge about menarche from their sisters and only $15.5 \%$ from their mothers; but this finding is similar to the conclusion as put forward by Thakre et al. (2012). This finding, nonetheless, does not inspire confidence as female literacy of the village is only $54.74 \%$ (Census of India, 2011). It can be argued that the participants were not well informed about the central reasons behind menstruation. Females were discussing menarche and menstruation, but it was little more than gossiping, and they needed someone well versed with science of menstruation to make them aware of the process and make them more comfortable with it. Among the younger females, the literacy rate was higher as compared to their previous generation. This observation resonates with the research findings of Bhattacharyya (2009; 2013a).

Interestingly, all the respondents had vague ideas about menarche before attaining it, and none of the respondents was aware of its physiological cause. It is essential to realise that most of the time, the emphasis is given on who is imparting the knowledge and the extent of knowledge the girls have of their own menstrual cycle, but fail to acknowledge the fact that it is challenging to explain a 12-13-year-old girl about the anatomy of her body in depth and the same level of difficulty for the girl to understand it. It is better to introduce them with their body gradually with the help of someone who has a basic understanding of female anatomy; can relate to it and let them know about themselves in the most comfortable and natural way possible. Similar ideas have been argued by Madsen (2011) who argued:

The more we teach woman about our menstrual cycle, not only will they be better able to understand their bodies, but they will have a better relationship with their sexuality and fertility (Madsen, 2011, para 2).

The research findings further unravelled that clothes were the preferred absorbents over sanitary napkins which are locally called 'sokhta'. About $42.5 \%$ of the respondents were using clothes, and $32.5 \%$ of the respondents were using commercial sanitary napkins. This is at variance with study conducted by A.C.Nielson in 2011 (as cited in Garikipati \& Boudot, 2017) which stated that only $12 \%$ of India's menstruating women use sanitary napkins and over $80 \%$ resort to shocking alternatives like unsanitised clothes, ashes, husk and sand. However, none of our respondents was using ash, husk or sand. Their usual response was "who uses these things?" or "can these be used?" or "Never heard of using these by someone!". Nonetheless, one-fourth of the respondents (25\%) were using both clothes and 
sanitary napkins, according to their own convenience. Generally these females were using clothes at home and napkin while venturing out of the village.

As per the National Family Health Survey (NFHS), 2015-16 report, the use of sanitary napkins among rural Indian women was $48.5 \%$. Seemingly, the findings of our research demonstrated that sanitary napkins were more prevalent among young girls than among middle-aged women. The reason behind preference for clothes amongst middle-aged women was the comfort, familiarity and cheapness. The only downside narrated was that sometimes clothes would not remain in place. Clothes were preferred due to easy availability as pieces of clothes were usually procured from old worn-out cotton sari or other garments, which were washed and dried in the sun before using. Young girls preferred sanitary napkins due to its staying at a place. They thought it as better than cloth due to heavy promotion in media which shows that the diffusion of the information through mass media has seeped in and the young minds were eager to follow them without any real knowledge.

However, the research findings unravelled that disposal of used sanitary napkins was largely ignored. Sanitary napkins that the participants use are non-biodegradable, and they practise dumping these napkins in fields or village pond and nearby canal, which obviously is one of the causes of environmental problems and the spread of pathogens. A study by Shah et al. (2013) indicated that the girls were more at ease with clean 'falalin' clothes than cheap sanitary napkins. Infrequent change of absorbents is a more significant issue amongst the respondents than the use of clothes or sanitary napkins. It is found that the respondents using sanitary napkins fail to change it frequently. Most of the respondents were not changing their absorbents even twice in a day. And this habit was not in line with the general conception that the frequency of changing the absorbents gets better with the availability of toilets (Table 1). Cleaning of hands before using or after changing absorbent is one of the hygienic practices which was not strictly followed. Only $20 \%$ of the respondents were washing their hands before and after the change of absorbents. Washing of hands and required change of absorbents are crucial in maintaining hygiene. The majority of the respondents claimed to have never reused the clothes. After using a cloth,they dispose it in the fields or ponds instead of washing, drying and re-using.

Table 1: Toilet Facility During Periods and Frequency of Change of Absorbents

\begin{tabular}{|c|c|c|c|c|}
\hline \multicolumn{4}{|c|}{ Table 1: Toilet Facility During Periods and Frequency of Change of Absorbents } \\
\hline $\begin{array}{c}\text { Type of Toilet Facility } \\
\text { during Menses }\end{array}$ & No. of Respondents & \multicolumn{2}{|c|}{ Frequency of Change of Absorbents } \\
\cline { 3 - 5 } & & 1 time & $1-2$ times & $<2$ times \\
\hline Open Defecation & 31 & 1 & 22 & 8 \\
\hline Own Toilet & 9 & 3 & 6 & 0 \\
\hline
\end{tabular}

\begin{tabular}{|c|c|c|c|c|}
\hline \multicolumn{5}{|c|}{ Table 2: Availability of Toilet Facility to Respondents } \\
\hline & \multicolumn{2}{|c|}{ Toilet Facility at Home } & \multicolumn{2}{|c|}{ Toilet Facility during Menses } \\
\hline & $\begin{array}{c}\text { Open } \\
\text { Defecation }\end{array}$ & Own Toilet & $\begin{array}{c}\text { Open } \\
\text { Defecation }\end{array}$ & Own Toilet \\
\hline No. of Respondents & 23 & 17 & 31 & 9 \\
\hline
\end{tabular}

The presence of toilets in the residential dwellings was not a universal phenomenon as only $42.5 \%$ of the respondents had toilets, and half of these respondents were not availing the existing toilet facility during menses (Table 2).
These observations bear resonance to the importance of Clean India or Swachh Bharat Abhiyan launched in 2014 by honourable Prime Minister of India, Mr Narendra Damodardas Modi (Bhattacharyya, 2014; Bhattacharyya and 
Pulla, 2019; Das,2018). One has to acknowledge that in the aftermath of the launch of the Swachh Bharat Abhiyan aimed at creating a clean and hygienic landscape by building 'basic hygiene and sanitation infrastructure' through the construction of toilets and complete elimination of open defecation (Bhattacharyya, 2014b; Bhattacharyya and Pulla, 2019; Das, 2018: 1 ; Koner, 2018). ${ }^{1 \text { "While the society has }}$ [gradually started] welcome[ing] these social initiatives, its reach and impact will perhaps take some time to reflect given India's geographical extent and bureaucratic challenges at both federal and sub-national level" (Das, 2018:1).

One of the questions that were explored washow the women of our sample cope during the days of menstruation, including the types of discomforts/symptoms they go through. In addition, we also explored, whether they faced any form of restrictions during the days of menstruation. The respondents were regularly bathing during menses, but about $80 \%$ of them were avoiding use of soap as its use render their skin dry and itchy. Only $5 \%$ of the respondents avoided bathing altogether. Many respondents explained that women of earlier generation were not taking a bath during menses because, in their opinion, bathing during menses interfere with flow and cycle. Women also followed food restrictions during menses as $70 \%$ of the respondents were totally avoiding meat and lowering the intake of dairy products because meat and dairy products, according to them, were heavy causing gastrointestinal disorders. Restricting intake of some food items is clearly outlined in Ayurveda, the ancient Indian system of health and medicine. Ayurveda has prescribed many dos and don'ts, called Rajaswala Paricharya (Pai, Bhatuda \& Prasad, 2015, Sonu, Hetal \& Kumar, 2016) which is to be observed during menstruation such as intake of light and easily digestible food, avoidance of physical labour, refraining from intercourse among others. The aim of Rajaswala Paricharya is to

\footnotetext{
${ }^{1}$ According to the available statistics, approximately 600 million Indians defecated in open spaces (Bhattacharyya, 2014) but statistics from Swachh Bharat Abhiyan (gramin) website shows that in 2019-20,13,46,666 toilets have been built (Swachh Bharat Mission-Gramin (All India),
}

protect health of women and their progenies. Ayurveda treats menstruating woman as a person with a wound and menstruation as a state of weak digestion. Hence, prescribes light and easily digestible food, avoidance of physical labour and refrain from intercourse. Nearly $60 \%$ of the respondents were restricting their activities like doing strenuous work, shopping, social visits, and others. Ayurvedic text Sushruta Samhita (Sharirasthana 2.24) advises women against doing household chores (Sridhar, 2019). In a study, conducted by Pai et al. (2015) amongst 30 unmarried females between 18 to 24 years, having regular menstrual cycles, it was found that, following dos and don'ts of Rajaswala Paricharya during the three days of menstruation, over six consecutive cycles, drastically reduced thirteen menstrual symptoms (breast tenderness, constipation/ increased bowel movements, cramps in calf muscles, excitability/irritability/depression, headache/migraine, hot flushes, increased frequency of micturition, loss of appetite, lower back ache, nausea/vomiting, pain in lower abdomen, pimples and weakness) except for symptom of breast tenderness. Effectiveness of Rajaswala Paricharya has also been studied by Sonu et al., (2016), in case of Dysfunctional Uterine Bleeding. In this study, heavy menstrual bleeding of a twenty-five-year-old female patient returned to normal through successful application of Rajaswala Paricharya.

All the respondents had expressed their willingness to avoid physical work and take complete rest. Previously, for older generations, there were complete restrictions for menstruating women on gaining access to the kitchen as menstruation was considered as unclean. Our findings in the study area unveil that restriction on access to the kitchen is slackening as $72.5 \%$ of the respondents were cooking food or performing related activities like cutting and peeling vegetables in the kitchen during menses. However, the respondents had

Department of Drinking Water and Sanitation, Ministry of Jal Shakti. Retrieved on 20 August 2019 from, https://sbm.gov.in/sbmReport/home.aspx). However, it is very difficult to change peoples' behaviour (see, Bhattacharyya and Pulla, 2019). 
expressed their desire to avoid cooking or related activities, especially during peak summer months, and take complete rest. This easing of restriction is mostly due to breaking up of joint and extended families. ${ }^{2}$ One of the earliest mentions about menstruation is in Taittiriya Samhita (2.5.1), which is repeated in Shatpatha Brahman (Keith, as cited in Sridhar, 2019). This mention in Taittriya Samhita (2.5.1) clearly recognises menstruation as a natural occurrence akin to pruning of sap or fissures in surface of Earth. The text recognises menstruation as a biological process and its relation to fertility. Menstruation is treated at par with a person without bath or with a person who has contacted something unclean and has not washed their hands (Ashaucha). Various ancient texts like Vashishta Dharmasutra, Angirasa Smriti and Ayurvedic texts such as Charak and Sushruta Samhita, advise women to resume their household work only after their monthly period ends and avoid physical exertion (Sridhar, 2019).

When it comes to MRSs and menstrual disorders such as dysmenorrhea (cramps and pelvic pain with menstruation), hypomenorrhea (scanty or infrequent menstruation), hypermenorrhea and menorrhagia (abnormally heavy and prolonged menstruation), $55 \%$ of the respondents complained of dysmenorrhea. As a way of relief, $52.5 \%$ ( 21 women) out of the $55 \%$ respondents took over the counter generic antipyretic and analgesic medicines like paracetamol and meftol-spos for relieving the pain. Some of the respondents were resorting to traditional remedies such as hot pack, haldi doodh (turmeric milk), ajowain seeds (carrom), fenugreek seeds and fennel seeds with water as a way of relieving themselves from pain-a way to obtain some form of relaxing. The majority of the respondents, however, had the habit of taking excess amount of tea (chai) during menses but complained of worsening of cramps after heavy tea consumption. Consuming tea might be one of the contributing factors behind the problem

\footnotetext{
2 Extended families are composed of at least three generations living together that is, grandparents, married offsprings and grandchildren whereas in joint families
}

of dysmenorrhea among the respondents. Only two respondents complained of heavy bleeding and one of an irregular cycle. Rest of the respondents complained of body heat, lethargy, bloating, stiffness in body, sleepiness and drowsiness.

Nonetheless, $90 \%$ of the respondents claimed to have at least mild premenstrual syndromes like irritation, body stiffness, irregular bowel movements, nausea, itching and headache. Menstrual rest is very important for women. The physical and mental pressure, coupled with schooling activities or the kitchen work is not generally advisable to women. Furthermore, on the other side, respondents were themselves not willing to be physically active and have confessed to rather have rest during menstruation. Schoep et al. (2019) have reported $80 \%$ presenteeism during menstruation among their sample of 32,748 women in Netherlands where 'presenteeism' denotes loss of productivity while present at work or school while MRSs were responsible for $24 \%$ of total absenteeism for working women and students. A similar study was conducted in London by Bruinvels, Burden, Brown, Richards \& Pedlar (as cited in Joseph, 2016) among Elite and Non-Elite Athletes in 2015, which covered 789 participants through an online survey and 1073 face to face interviews. Heavy Menstrual Bleeding ( $\mathrm{HMB})$ was reported by half of the online (54\%), and by nearly a third of the marathon runners (36\%). It is interesting that $\mathrm{HMB}$ was also prevalent among elite athletes (37\%). $32 \%$ of all the exercising females reported a history of anaemia, and $50 \%$ had previously taken iron supplements (Bruinvels et al., as cited in Joseph, 2016). In Australia, the Menstrual Disorder of Teenagers (MDOT) study surveyed 1051 adolescents between the age group of 1618 years and found that $94 \%$ reported menstrual pain, 96\% experienced Pre-Menstrual Symptoms (PMS), 58\% reported clots in the menstrual discharge and irregular periods was reported by $30.5 \%$ of the respondents (Parker, Sneddon \&

siblings, their spouses and their dependent children live together (Bhattacharyya, 2009; 2013a). 
Taylor, as cited in Joseph 2016). Schoep et al. (2019) stated that the impact of MRSs on women should be focussed upon.

The Red Tent Movement (Red Tent Temple Movement, n.d.), which has gradually become popular in the west in recent years has drawn itself on the lines of confining in and honouring the natural cycle, aligning the fertility cycles with the lunar cycle, giving attention to womanhood, taking care of oneself and one another. This concept has always been in ancient Indian traditions. The concept of menstrual huts and seclusion of menstruating women by confining them in a particular room was done on the same lines of resting and taking care of oneself in older traditions. One of the names used for menstruation in Ayurvedic texts is Artava, which is derived from the Sanskrit word ' $r$ tu' meaning 'season'. "Rtu also implies ritual suggesting that the rhythm of life comes from the ritual dance of the seasons, and in particular lunar season" (Sandhiya Ramaswamy, 2010, p. 6)

Similarly, Bailey (2012) writes about the connection between the menstrual cycle and the lunar cycle as enunciated by the Ayurvedic text:

Ayurveda suggests that in the ideal cycle, the female human body would be synchronised to the cycles with the moon, ovulating on or near the full moon and menstruating on or near the new moon, a twenty-eight-day cycle in all (Bailey, 2012, p.3).

Hegde (2004), mentions about great philosopher Varahmihira, who lived around 100 BC, discussed the Moon's control on the woman's body. The same was mentioned by Cecil (as cited in Hegde, 2004), who gives a detailed description on the physiology of menstruation, in which he has mentioned the gravitational influence of the moon which gives rise to the menstrual cycle.

Our research, however, found that the respondents were not visiting temples, performing daily household worships, sacred rituals or performing namaz. These were family restrictions as well as self-imposed ones. However, the participants were unaware of the traditional significance of these restrictions and, also, about many festivals celebrating menarche and menstruation. They were awestruck on being told about these festivals and celebrations. In India, across various states, coming of age and menarche is celebrated. Such ceremonies as Sridhar (2019) has remarked have one thing in common that these are aimed at imparting positive notions regarding menstruation to young girls by "imparting knowledge that equips the young girl to adjust well to her on-coming physical and emotional changes during puberty" (Sridhar, 2019, p.35), which is widely celebrated in Kerala, Odisha, Karnataka, Andhra Pradesh, Tamil Nadu, Assam, Bengal, and Madhya Pradesh. The most widely known is Ritu Kala Samskara (Pandey, 2001). There is a famous Ambubachi Mela dedicated to goddess Kamakhya, which is celebrated in the state of Assam during the monsoon in the month of June. The temple remains closed for three days every year as the deity is believed to be undergoing menstruation; hence, complete rest is provided for those three days. People do not till the land as the goddess Kamakhya is also Mother Earth (Malik, 2017; Sridhar, 2019). N.N. Bhattacharya in his book India Puberty Rites mentions about these rituals too.

While mentioning the dilemma regarding taking rest and productivity, Joseph (2017) further asserts that when women push their bodies beyond their limits while menstruating, it creates more damage than good due to both short- term and long-term effects on health which sometimes results in more sick-leaves and also hampers productivity. Hormones are responsible for an individual's productivity, especially during menstruation. "A woman's physical and mental abilities are at their peak just after menstruation with the rise of the hormone estrogen, and at their lowest just before and during menstruation due to the influence of the hormone progesterone" (Joseph, 2017, para 10). Schoep et al. (2019) too found that apart from financial burdens generated from seeking medical advice and medicines, costs in terms of productivity loss could be one of the major cost drivers. "It seems likely the real impact of MRSs is underestimated 
in the general population" (Schoep et al., 2019, p. 2). Hence, it can be inferred that taking breaks and rest during menstruation will actually do more good by enhancing overall productivity at work and further it will also be beneficial for health too. Resting, avoiding physical exertion and specific diet restrictions should not be kept under the domain of taboos. The abovementioned methods were helping women in ancient societies in maintaining their health which they achieved by intertwining and weaving together science into culture and religion, "whether it is India's Ayurveda, China's Acupuncture or the indigenous science of the Caribbean islands-there is far deeper understanding of the menstrual cycle than we have cared to investigate" (Joseph, 2016, para 40). One can, therefore, argue that menstruation is an important aspect of a woman's body and life and a period of rest, austerity and selfpurification and privilege available only to them (Marglin, 1994; Sridhar 2019).

\section{Conclusion}

The study analyses how menstruation is lived, experienced and managed by women in village Khagawal located at Chandauli district, Uttar Pradesh. It explores how women who live in secluded rural areas navigate through the entire process and come to an understanding with it, further examining various coping mechanisms which help them in mitigating their problems. The findings of the study suggest that cotton clothes which is washed and sun-dried remains the first choice of absorbent. The respondents preferred it for its easy availability, familiarity and absorption although sanitary napkins closely follow with more than $50 \%$ respondents using it at varying rate. This finding indicates that the discourses surrounding menstruation in popular culture need to move beyond sanitary napkins as the sole matter of discussion and should additionally focus on various menstrual-related symptoms and disorders.

Although the current study is based on a small sample of participants, the findings nonetheless make an added contribution to the study of menstruation. Of course, this study can be replicated in other locations across the country for a greater in-depth study, where one explores beyond the use of sanitary napkins and finds ways to empower girls and women during puberty and menstruation (Coast et al., 2019).

\section{References}

Bailey, J.G. (2012). By the light of the moon: Ayurveda, yoga and menstruation. Retrieved on 20 September 2018 from, http://ayurmater.blogspot.in/2012/07/by -light-of-moon-ayurveda-yoga-and.html/

Banerjee, I., Chakraborty, S., Bhattacharyya, N. G., Bandyopadhyay, S., Saiyed, H.N. \& Mukherjee, D. (2007). A cohort study of correlation between body mass index and age at menarche in healthy Bengali girls, Journal of Indian Med Association 105: 758.

Bhattacharyya, N. N. (1980). Indian puberty rites. New Delhi, India: Munshiram Mahoharlal New Delhi.

Bhattacharyya, R. (2009). Examining the changing status and role of middle-class Assamese women: Lessons from the lives of university students, $\mathrm{PhD}$ thesis. Newcastle University, UK.

Bhattacharyya, R. (2013a). Are we empowered? Stories of young Indian working women. Saarbrücken, Germany: Lap Lambert Academic Publishing.

Bhattacharyya, R. (2013b). Criminal Law (Amendment) Act, 2013: Will it ensure women's safety in public spaces? Space and Culture, India, 1(1), 13-27, https://doi.org/10.20896/saci.v1i1.11

Bhattacharyya, R. (2014a). Life and times of unborn Kamla. Space and Culture, India, 2(2), 57-58, https://doi.org/10.20896/saci.v2i2.89

Bhattacharyya, R. (2014b). Good governance and development mandate. Space and Culture, India, 2(1), 1-4. https://doi.org/10.20896/saci.v2i1.65

Bhattacharyya, R (2015). Understanding the spatialities of sexual assault against Indian women in India. Gender, Place \& Culture: 
A Journal of Feminist Geography, 22(9), 1340-1356, http://dx.doi.org/10.1080/0966369X.201 4.969684

Bhattacharyya, R. (2016). Street violence against women in India: Mapping prevention strategies. Asian Social Work and Policy Review, 10(3), 311-325, doi: 10.1111/aswp.12099

Bhattacharyya, R. (2018). \#MeToo movement: An awareness campaign. International Journal of Innovation, Creativity and Change 3(4): 1-12. Retrieved on 30 August 2019 from, http://www.ijicc.net/images/Mrach18_sp ec_edition/battacharyarra_March18.pdf

Bhattacharyya, R., \& Pulla, V. (2019). Prime Minister Modi returns, 2019: New governance agenda. Space and Culture, India, 7(1), 1-14. https://doi.org/10.20896/saci.v7i1.569

Bhattacharyya, R. and Singh, S. (2018).

Exclusion (and seclusion): Geographies of Disowned Widows of India, GeoJournal, 83 (4), 757-774, DOI: 10.1007/s10708017-9800-0

Bhattacharyya, R., Das, T. K., Alam, M. F., \& Parvin, A. (2018). Researching domestic violence in Bangladesh: Critical reflections. Ethics and Social Welfare, 12(4), 314-329, https://doi.org/10.1080/17496535.2018.1 458889

Bloch, F. \& Rao, V. (2002). Terror as a Bargaining Instrument: A case-study of dowry violence in rural India, American Economic Review, 92(4), 1029-1043.

Coast, E., Strong, J. \& Lattof, S.R. (2019, February 26). Looking beyond padman: a need to empower girls during menstruation and puberty. South Asia [Blog Post]. Retrieved on 15 September 2019 from, http://eprints.Ise.ac.uk/101821/1/southa sia_2019_02_26_looking_beyond_padma n_a_need_to_empower_girls.pdf/
Census of India. (2011). District Census Handbook Chandauli, Village and Town wise Primary Census Abstract (PCA), Directorate of Census Operations Uttar Pradesh, Series 10 Part XII-B

Dambhare, D. G., Wagh, S.V. \& Dudhe, J. Y. (2012). Age at Menarche and Menstrual Cycle Pattern among School Adolescent Girls in Central India, Global Journal of Health Science 4(1): 105-11, doi: 10.5539/gjhs. v4n1p105

Das, D. (2018). India's recent development dynamics and challenges. Space and Culture, India, 5(3), 1-4. https://doi.org/10.20896/saci.v5i3.304

Das, T. K., Alam, M. F., Bhattacharyya, R., \& Parvin, A. (2015). Causes and contexts of domestic violence: Tales of help-seeking married women in Sylhet, Bangladesh, Asian Social Work and Policy Review, 9 (2), 163-176, doi:10.1111/aswp.12055

Das, T. K., Bhattacharyya, R., Alam, M. F., \& Parvin, A. (2016). Domestic violence in Sylhet, Bangladesh: Analysing the experiences of abused women, Social Change, 46(1), 106-123, doi: $10.1177 / 0049085715618561$

Dyson, J. (2019). Rethinking education as a contradictory resource: Girls' education in the Indian Himalayas, Geoforum, 103, 6674.

Garg, S., Sharma, N., \& Sahay, R. (2001). Sociocultural aspects of menstruation in an urban slum in Delhi, India. Reproductive Health Matters, 9(17), 16-25, doi:10.1016/S0968-8080(01)90004-7

Garikipati, S. \& Boudot, C. (2017). To pad or not to pad: Towards better sanitary care for women in Indian slums. Journal of International Development, 29, 32-51, doi: 10.1002/jid.3266

Hegde, B. M. (2004). Woman, moon and menstruation. Indian Academy of Clinical Medicine. 5(1), 22-23

Hoerster, K. D., Chrisler, J. C., \& Rose, J. G. (2008). Atitude toward and experience 
with menstruation in the US and India. Women and Health, 38:3, doi: 10,1300/J013v38n0306

International Institute for Population Sciences (IIPS) \& ICF. (2017). National Family Health Survey (NFHS-4), 2015-16. Mumbai, India. IIPS.

Joseph, S. (2014, April 11). Myths about menstrual hygiene management [Blog post]. Retrieved on 30 March 2019 from, https://mythrispeaks.wordpress.com/201 4/04/11/menstruation-stereotypes-andunlearning/

Joseph, S. (2016, June 13). Menstruation: Rhetoric, research, reality [Blog post]. Retrieved on 30 March 2019 from, https://mythrispeaks.wordpress.com/201 6/06/13/menstruation-rhetoric-researchreality/

Joseph, S. (2017, August 7). Menstrual Leave The First Step To Work In Sync With Nature [Blog post]. Retrieved on 30 March 2019 from, https://mythrispeaks.wordpress.com/201 7/08/07/menstrual-leave-the-first-stepto-work-in-sync-with-nature/

Kansal, S., Singh, S. \& Kumar A. (2016). Menstrual hygiene practices in context of schooling: A community study among rural adolescent girls in Varanasi. Indian Journal of Community Medicine, 41 (1), 39-44, doi:10.4103/0970-0218.170964

Koner, K. (2018). Sanitation and hygiene of Darjeeling city: A crisis for women and adolescent girls. Space and Culture, India, 5(3), 89-105, doi: 10.20860/saci. v5i3.292

Madsen, P. (2011). The importance of listening to our menstrual cycle. Retrieved on 30 March 2019 from, https://www.psychologytoday.com/intl/bl og/shameless-woman/201101/theimportance-listening-our-menstrual-cycle

Malik, R. (2017). Meeting the many peoples of Assam. Retrieved on 30 March 2019 from, https://www.hinduismtoday.com/module s/smartsection/item.php?itemid $=5769$
Marglin, F. A. (1994). The Sacred Groves, Manushi, 82, 22-32.

Pai, P., Bhatuda, S. \& Pandkar, P. (2015). Rajaswala paricharya: Effect on menstrual cycle and its associated symptoms. IOSR Journal of Dental and Medical Sciences, 14, 2(2). 82-87.

Pandey, R. (2001). Sacred Samskaras. Retrieved on 30 March 2019 from, https://www.hinduismtoday.com/module s/smartsection/item. php?itemid $=4043$

Pugalenthi, T., Senthil, J., Jayakumar, K.K., \& Pandiammal, C. (2013). Determinants of menstrual hygiene practice among unmarried women in India. Scholars Research Library 5(4), 137-145.

Raina, D. \& Balodi, G. (2014). Menstrual hygiene: Knowledge, practise and restrictions amongst girls of Dehradun, Uttarakhand, India. Global Journal of Interdisciplinary Social Sciences 3(4), 156162.

Ramaswamy, S. (2010). Ayurveda - An ancient healing system's gifts to the modern woman. Retrieved on 30 March 2019 from, http://www.ayurvedacollege.com/sites/a yurvedacollege.com/files/articles/Ayurve da-SandhiyaRamaswamy.pdf

Rao, V. (1993). The rising price of husbands: A hedonic analysis of dowry increases in rural India. Journal of Political Economy, 101, 666-677.

Rao, V. (1998). Wife-Abuse, its causes and its impact on intra-household resource allocation in rural Karnataka: $\mathrm{A}$ "Participatory" econometric analysis. In M. Krishnaraj, R. Sudarshan \& A. Sharif (Eds.), Gender, Population, and Development, Oxford University Press, Delhi and Oxford.

Red Tent Temple Movement. (n.d.). Retrieved on 30 March 2019 from http://www.redtenttemplemovement.co $\mathrm{m} /$ 
Schoep, M. E., Adang, E. M. M., Maas, J.W.M., Bie, B. D., Aatrs, J. W. M. \& Nieboer, T. E. (2019). Productivity loss due to menstruation-related symptoms: A nationwide cross-sectional survey among 32,748 women. BMJ Open 2019;9:e026186, doi:10.1136/bmjopen2018-026186

Shah, S. P., Nair, R., Shah, P. P., Modi, D. K., Desai, S. A. \& Desai, L. (2013). Improving quality of life with new menstrual hygiene practices among adolescent tribal girls in rural Gujarat, India. Reproductive Health Matters, 21(41), 205-213.

Singh, S. (2018). Self-proclaimed God convicted, POCSO amended. Space and Culture, India, 6(1), 7-15, https://doi.org/10.20896/saci.v6i1.319

Sonu, D., Hetal H. \& Kumar, V. (2016). Efficiency of Rajaswala paricharya in asrigdara (dysfunctional uterine bleeding): A case study. Journal of Biological and Scientific Opinion, 4(3), 97-98.

Sridhar, N. (2019). The Sabrimala Confusion Menstruation Across Cultures: A Historical Perspective. New Delhi, India. Vitasta Publishing.

Srinivasan, S. (2005). Daughters or dowries? The changing nature of dowry practices in
South India. World Development 33(4), 593-615, doi:

10.1016/j.worlddev.2004.12.003

Thakre, S. B., Thakre, S. S., Ughade, S., \& Thakre, A. M. (2012). Urban-rural differences in menstrual problems and practices of girl students in Nagpur, India. Indian Paediatrics, 49, 733-36.

Varma, K.K. (2013). Life and Times of Unborn Kamla. New Delhi, India. Palimpsest Publishers.

Vauquline, P. (2015). Socialisation process, power relations and domestic violence: Marginal voices of Assamese Women. Space and Culture, India, 3(2), 54-71, doi: 10.20896/saci. v3i2.155

Vishwanath, L. S. (1996). Female infanticide and the position of women in India. In A. M. Shah, B. S. Baviskar \& E. A. Ramaswamy (eds.). Social structure and change: Women in Indian Society (vol.2, pp. 179205). New Delhi, India. Sage Publications.

Yasmin, S., Manna, N., Mallik, S., Ahmed, A. \& Paria, B. (2013). Menstrual hygiene among adolescent school students: An indepth cross-sectional study in an urban community of West Bengal, India. Journal of Dental and Medical Sciences, 5(6), 2226 